\title{
O TRABALHO NOTURNO DO ENFERMEIRO: busca de significados sobre o repouso antes, durante e após o plantāo *
}

\author{
Zelina Pontes **
}

\begin{abstract}
RESUMO - Neste estudo que resultou de uma pesquisa qualitativa com abordagem fenomenológica, a autora analisa os significados do trabalho noturno e do repouso para onze Enfermeiros

de. Conclui que o significado do trabalho noturno é de grande importância, que ele é considerado muito cansativo, desgastante e estressante. Que o repouso é de importância e necessário sendo que, para a maioria, ele ocorre somente após o plantão, na noite de folga. Que o autocuidado já está comprometido pelo fato de trabalharem à noite e agravado pela necessidade de possuírem outro emprego durante o dia. Finalmente, sugere que Enfermeiros e Empregadores atentem para esta problemática.
\end{abstract}

\begin{abstract}
In this study, which is the result of a qualitative research with a phenomenological approach the author analyses the real meaning of night-work and the resting regarding eleven nurses from five different Health Center. She concludes that the importance of night-work is of a such responsability once it is considered a lot tiring, absorving and stressing activity. The author also mentions that the rest is very much necessary, once that for most of the professionals it happens only after duty in the night off, and that the self-care of everyone is already endangered by the fact of them, working at night and are exacerbated by the necessity of having another job during the day. Finally the author suggests that both nurses and Employers should focus on this problematic question.
\end{abstract}

\section{INTRODUÇĀO}

As condições de trabalho e de vida do pessoal de Enfermagem deveriam ser uma preocupação constante dele próprio e dos empregadores dos Serviços de Saúde, no entanto a nossa realidade não nos mostra isso.

São citadas freqüentemente a $61^{\mathrm{a}}$ - Conferência da Organização Internacional do Trabalho realizada em junho/76 e a $63^{\text {a }}$ realizada em junho de 1977 em Genebra. Desta última saíram a Convenção OIT no 149 e a Recomendação OIT no 157 (Oguisso Schmidt, 1984). Considerando que a recomendação da OIT pode ser ou não realizada pelos países e quando $\epsilon$ a título de convenção o cumprimento é obrigatório. No entanto, itens importantes para a saúde do trabalhador saíram apenas como recomendações.

Entre elas encontram-se pausas de duração razoável durante as horas de trabalho normais, para compensar o trabalho realizado em condições particularmente penosas ou desagradá- veis; redução da jornada diária de trabalho ou aumento do perfodo de repouso sem diminuição de remuneração, além de outras.

Esta profissão que contribui para preservar a vida e a saúde do homem ainda não conseguiu uma conscientização dos riscos a que se expõe e nem uma resolução dos problemas com a sua própria proteção.

O trabalho do Enfermeiro em hospitais se caracteriza pela natureza da função (o lidar com a dor, o sofrimento e a morte); sistema de turno contínuo ou de trabalho em turnos ininterruptos de revezamento; existe prestação de serviços durante vinte e quatro horas diárias e nos sete dias da semana; existe um período de transição entre cada dois turnos para a passagem do plantão; com pequenas variações o inf́cio do plantão noturno sempre $\varepsilon$ às $19 \mathrm{~h}$ e o término às $7 \mathrm{~h}$; entre outras. Estas características são as que nos interessam de imediato por centrarmos o estudo no trabalho noturno.

* Tema livre apresentado no 43 Congresso Brasileiro de Enfermagem - Curitiba-PR.

** Enfermeira do Trabalho.

80 R. Bras. Enferm., Brasília, 45 (1): 80-87, jan./mar. 1992 
A ergonomia procura adaptar o trabalho às exigências fisiológicas do ser humano.

O trabalho notumo e o trabalho em turnos são discutidos no contexto dos riscos ergonômicos e estes estão relacionados com a organização do trabalho.

Assim têm sido estudadas as alterações e/ou perturbações na saúde do trabalhador notumo, através da cronobiologia, a ciência dos ritmos. Foi observada a impossibilidade de uma inversão completa dos ritmos circadianos do indivíduo, quando se trabalha à noite. Com a desincronização destes ritmos ocorrem perturbações sérias do sono e da vigflia.

Uma tarefa realizada facilmente às dezesseis horas, poderá ser extremamente penosa às quatro horas da manhã, quando fisiologicamente $O$ indivíduo está preparado para estar dormindo (FERREIRA ${ }^{1}$.

Toda noite a luta contra o sono recomeça, mesmo que a pessoa tenha 20 anos de trabalho noturno.

Além dos prejuízos à saúde ocorrem as dificuldades no relacionamento familiar e social; no lazer, na participação em Associações de Classe, etc., devido ao desencontro de horários.

LAUREL $^{5}$ nos diz que quando o consumo de força de trabalho compromete a saúde do trabalhador vinculado à extração da mais valia, tendo em vista as exaustivas jornadas e os salários não condinzentes, o trabalho passa a ser patológico. Como o trabalhador não percebe, a curto prazo, este passa a ser um fenômeno preocupante para os pesquisadores que efetivamente têm demonstrado, através de seus estudos, os riscos; contudo ainda são poucos os interessados mesmo entre os que estão expostos a esta problemática.

Toda vez que a organização de uma atividade implicar trabalho noturno, deve-se estar ciente de que este trabalho é prejudicial ao trabalhador (FERREIRA ${ }^{1}$ ).

Vem daí a nossa preocupação com o repouso porque este é um fator importante para minimizar os danos à saúde. Sendo o repouso durante o plantão muito importante e necessário.

Buscar o significado do repouso antes, durante e após o plantão noturno é antes de tudo um caminhar juntos em busca de soluções para esta situação vivida no dia-a-dia do Enfermeiro.

Porque para trabalhar, nos lembra SILVA ${ }^{8}$, o homem precisa gozar de saúde e na ausência dela não há trabalho e, sem ele, o homem perde a condição de atender às suas necessidades básicas e às de sua famnlia.

Sendo que as questōes que nortearam o nosso estudo foram:

- Qual é a compreensão dos Enfermeiros sobre o repouso antes, durante e após o plantão?

- Como envolver pesquisador e sujeitos - enfermeiros num processo dialógico de transfor- mação das condições do trabalho noturno?

Tendo como ponto principal de investigação as implicações decorrentes do trabalho noturno em turnos, pretende-se buscar com os Enfermeiros de Hospitais de grande porte da região metropolitana de Curitiba o que realmente acontece na sua vivência. Mais especificamente o presente estudo tem como objetivos:

- Buscar de cada Enfermeiro o significado do trabalho noturno e do repouso antes, durante e após o plantão;

- Reconhecer nos depoimentos dos Enfermeiros o que realmente ocorre na sua vivência do trabalho notumo em relação ao repouso;

- Compreender com o Enfermeiro o grau de importância relativa ao seu repouso no seu autocuidado;

- Buscar com os envolvidos uma compreensão sobre o fenômeno do trabalho noturno para que Enfermeiros, Instituições, Sindicatos e Associações se empenhem na conquista de melhoria das condições de trabalho;

- Identificar as condições e a duração do repouso pré, durante e após o plantão;

- Constatar no local de trabalho a existência ou não de uma rotina organizada que propicie o repouso durante o tumo.

\section{RE VISĀO DA LITERATURA}

Conforme GRANDJEAN ${ }^{3}$ a Ergonomia tem a função de prevenir a doença, ou mesmo impedir que ela se instale, procurando adaptar o trabalho às exigências fisiologicas do ser humano. Analisando, em meio aos métodos fisiologicos e psicologicos, as reações no trabalho e os efeitos do ambiente no trabalhador.

Dentro da ergonomia o trabalho em turnos e o trabalho notumo são vistos na organização do trabalho e é esta que determina o planejamento e a execução desses turnos.

Em conseqüência, os trabalhadores submetidos ao trabalho notumo estão sujeitos aos riscos ergonómicos especfficos dessa jornada.

O trabalho em turnos para RUTENFRANZ e $\mathrm{Col}^{7}$, são cada uma das funções de organização da jornada diária de trabalho, em que são realizadas atividades em diferentes horários ou em horários constantes porém incomuns (por exemplo, período noturno permanente).

O turno resulta sempre do fato de que a mesma atividade deva ser executada em diferentes períodos do dia e da noite, por vários empregados, em igual jornada.

Entende-se por jornada de trabalho o periodo que vai do início ao término do trabalho sem descanso; o turno, ao contrário, é o período em que o empregado tem que estar presente na empresa; o turno inclui tanto a jornada como as pausas, os descansos.

O periodo notumo de trabalho é o compreendido entre às $22 \mathrm{~h}$ de um dia e às $5 \mathrm{~h}$ do dia 
seguinte (artigo 73 da CLT, pi ágrafo 29 ).

Embora o Enfermeiro que trabalhe à noite inicie as suas atividades antes das $22 \mathrm{~h}$ e termine após às $5 \mathrm{~h}$, geralmente das $19 \mathrm{~h}$ às $7 \mathrm{~h}$, sua remuneração do período final no trabalho noturno se fará sem o adicional correspondente.

A hora noturna tem duração de $52 \mathrm{~min}$ e 30 seg (artigo 73, parágrafo $1^{\circ}$, da CLT). Isto equivale dizer que, trabalhando 12 horas à noite, recebe-se o pagamento por 13 horas.

Salvo nos casos de revezamento semanal ou quinzenal, o trabalho noturno terá remuneração superior à do diurno e para esse efeito, sua remuneração terá um acréscimo de $20 \%$ (vinte por cento), pelo menos, sobre a hora diurna (artigo 73 da CLT).

O homem, de acordo com a sua natureza, é ativo durante o dia, suas funçōes físicas são orientadas especialmente para o trabalho durante o dia e está relacionado com os ritmos biológicos.

A cronobiologia ou a ciência dos ritmos biológicos estuda a organização temporal dos fenômenos biológico-físiológicos e/ou psicológicos.

O organismo apresenta estados funcionais que variam ao longo do tempo respondendo a estimulos ambientais conforme o momento do dia, da semana em que estes estímulos ocorram. Estas variações do organismo respeitam determinados ritmos. Quando o perfodo do ritmo está em torno de 24 horas, ele é chamado de circadiano (do latim, circa $=$ em torno de e dien $=$ dia).

Todas as funções biológicas e/ou psicológicas como: a freqüência cardfaca, o humor, a força muscular apresentam uma ritmicidade circadiana com picos máximos e mínimos. Diversos ritmos das funções mantêm relaçōes precisas entre si e também com as variações temporais ambientais. Existe, assim, uma sincronização. E mesmo sem a interferência do ambiente (experiências em laboratório), estes ritmos se mantêm, embora dessincronizados entre si.

A interferência ambiental é externa e determinada por sincronizadores tais como o fenômeno claro-escuro e os de natureza social.

Ao contrário dos animais, o homem não consegue a inversão dia-noite somente pelo fenômeno claro-escuro, na realidade nunca se obtém uma inversão completa dos ritmos.

Experiências demostraram que a velocidade de "ajustamento" dos ritmos de umas funçōes como do humor, da pressão arterial, da força muscular é maior que da temperatura, do débito expiratório que exigem vários dias para "ajustarem", Reimberg e Col apud FERREIRA'.

RUTENFRANZ e $\mathrm{Col}^{7}$ verificaram em testes experimentais que uma adaptação parcial dos ritmos biológicos só acontece para a hora de dormir, mas não para a jornada de trabalho.
Essa adaptação precisa de pelo menos de dez a catorze dias. Entretanto, seria totalmente perdida a adaptação ao turno noturno, com a reversão do horário de dormir de dia para o perfodo normal à noite, em um único dia de folga

Como os trabalhadores não vivem em grupos experimentais fechados e, portanto, sofrem a interferência dos indicadores sociais de suas famnlias e das folgas, dessa forma é mais propício organizar turnos com escalas em sistema de rodízio, espaçando os turnos notumos.

Para entender melhor esta problemática, faz-se necessário abordar o sono e o ciclo sono-vignlia.

O ritmo circadiano da altemância sonovigflia é visto como uma das funções básicas do sistema circadiano. Nos turnos, este sistema é claramente perturbado.

Sabe-se que o sono apresenta 5 fases distintas, segundo a atividade elérica cerebral: os estados $1,2,3$ e 4 chamados como sono de ondas lentas e o estado 5 que é o sono paradoxal.

O sono de ondas lentas é o repousante e o sono paradoxal é um sono profundo, onde ocorrem os sonhos. Ele é o responsável pelo relaxamento psíquico.

Após 90 a $100 \mathrm{~min}$ do iń́cio do sono surge o sono paradoxal com duração de 5 a $20 \mathrm{~min}$, onde ocorre o REM (Rapid eye movements), há uma atividade encefálica semelhante à da vigilia, o porquê é ainda desconhecido; ocorrem neste período, os sonhos e a duração destes episódios aumenta proporcionalmente com a duração do sono total.

Estes sonos se intercalam e enquanto um aumenta o outro diminui.

Quando a pessoa é obrigada a trabalhar de noite e dormir de dia, ou seja, quando há uma mudança de sincronizadores, modifica-se a estrutura interna do sono.

O sono diumo é mais curto, com duração de 3-4 horas. Há uma modificação das diferentes fases com relação à duração, em geral às custas do sono paradoxal.

A diminuição da duração do sono paradoxal e até a sua ausência ocorre quando a pessoa está extremamente cansada GUYTON ${ }^{4}$.

À medida que avança o perfodo de trabalho noturno, essas perturbações são menos intensas, há uma tendência a "nomalização" do sonn, a tal ponto que o primeiro episódio do sono noturno após um período de sono diurno não tem todas as caracterfsiticas de uma verdadeira noite de recuperação (Foret e Lantin apud FERREI$\mathrm{RA}^{\prime}$ ).

Essas perturbações do sono diurno são também agravadas pelas condiçōes de ambiente, com rứdos e iluminação.

Por estes motivos, o trabalhador noturno terá uma privação crônica do sono, além da qualidade deste sono estar afetada. 
Esta privação do sono tem fortes repercussões na vignlia subseqüente. Dormir pouco ou dormir mal se traduz por dificuldades em realizar tarefas, principalmente aquelas que exigem uma atenção intensa e requerem um esforço muito grande para serem executadas, o que provoca um desgaste muito maior FERREIRA'.

Sabemos da nossa experiência que a lentidão de raciocínio que ocorre por volta de 3-4 horas da madrugada, provocada pela fadiga dos neurônios, faz com que um esforço maior seja dispendido.

Esta constante tentativa de adaptação sem sucesso pelo organismo leva a um importante desgaste e também, ao mesmo tempo, leva a tensões entre a capacidade produtiva $\mathrm{e}$ as exigências de rendimento, geralmente equivalentes de dia e à noite.

Assim, o trabalho noturno causa sempre esforços físicos e psíquicos elevados, podendo até ser considerado um fator de risco no aparecimento de doenças.

Denominam-se fatores de risco as qualidades congênitas, comportamentos adquiridos ou condições de vida e de trabalho previas que limitam a capacidade de adaptação de uma pessoa, do ponto de vista de saúde. A existência destes fatores não provoca doença mas há maior possibilidade de surgir uma enfermidade quando há um fator de risco (RUTENFRANZ $\mathrm{Col}^{7}$ ).

Estudos na área da cronotoxicologia têm mostrado que tóxicos medicamentosos agem diferentemente sobre o organismo segundo o período do dia no qual estão em contato.

Isso leva ao raciocínio que haja uma diferença para com os trabalhadores do período noturno.

Poderia se pensar também na existência de uma doença especificamente provocada pelo trabalho noturno.

Após estados de vignlia forçados por prolongados períodos de tempo, a pessoa pode tornar-se mal-educada e, inclusive, psicótica GUYTON ${ }^{4}$.

Em relação aos trabalhadores do dia, os turnistas se queixam mais de perturbações gastrointestinais, de fadiga, de problemas de sono e de nervosismo. Estas perturbações encontram justificativa na irregularidade de horários, na qualidade da alimentação (por exemplo: uma alimentação fria servida a 1 hora da manhã no próprio local de trabalho fora do convívio social e familiar) e na ritmicidade circadiana do aparelho digestivo que está tentando se adaptar, entre outras.

Durante a noite, normalmente, a secreção de suco gástrico necessário para a digestão praticamente não ocorre.

A fadiga e o nervosismo são conseqüentes da quantidade e da qualidade do sono.
Os problemas do sono são provocados pelas alterações no ritmo circadiano do ciclo sonovignia.

O trabalho noturno deixa seqüelas nas pessoas. São marcas de desgaste físico e mental. Deixa as pessoas mais susceptrveis a agentes nocivos, com cansaço crônico, marcas de sofrimento mental e de envelhecimento precoce.

O desgaste diário do trabalhador noturno será menor especialmente se forem preservadas as pausas durante o trabalho.

FISCHER et alii ${ }^{2}$, realizaram um estudo em uma empresa de transporte, onde era dada permissão aos motoristas de caminhão para dormirem curtos perfodos à noite, caso sentissem necessidade. Eles então, estacionavam o veŕculo no acostamento e, por 15 a $45 \mathrm{~min}$, dormiam. Retornavam ao trabalho mais dispostos e relatavam menos fadiga ao fim da jornada noturna.

A introdução de perfodos de sono no turno da noite pode parecer utópica no momento. No Japão, estas normas já existem há muito tempo em numerosas empresas, de modo mais ou menos oficial.

$\mathrm{Na}$ Enfermagem não foram encontrados relatos sobre $o$ assunto.

Sabemos, no entanto, que a jornada noturna é superada melhor com uma pequena pausa. Uma hora de sono durante a jornáda é mais importante que várias horas de luta contra o sono RUTENFRANZ e Col'?

\section{METODOLOGIA}

\subsection{Material e Método}

O estudo realizou-se junto à população de Enfermeiros do turno noturno de cinco Instituições Hospitalares de Saúde, sendo uma especializada e as demais gerais.

As Instituições selecionadas foram aquelas que tinham um número maior de Enfermeiros trabalhando à noite.

Em quatro dessas Instituições recebemos uma autorização informal por parte dos Diretores dos Serviços de Enfermagem, possibilitando assim o inf́cio imediato do estudo. Na outra a autorização foi formal.

Das instituições contatadas somente uma negou-se a oferecer o campo de pesquisa.

Foram entrevistados 21 Enfermeiros que trabalhavam à noite por mais de 3 meses e que mostraram interesse em colaborar com o estudo.

Foi na Fenomenologia que embasamos o nosso estudo. Na fenomenologia não há a preocupação em efetuar uma amostra representativa de um possível universo ao qual, eventualmente, se possam aplicar os achados ou descobertas da investigação MARQUES ${ }^{6}$. A realidade não é somente aquela percebida, mas é também a pensada e a sentida. 
Pensamos em buscar o que realmente acontece na vivência desse Enfermeiro, nesta situação, em uma experiência que é única, porém una.

Para Husserl citado por ZILLES $^{9}$ a fenomenologia preocupa-se em saber qual o significado daquilo que temos na consciência quando julgamos, afirmamos, sonhamos, vivemos.

A atitude fenomenologica, diz Husserl, é "voltar às coisas nelas mesmas", ou seja, mostrar a experiência que a pessoa tem vivido.

Edmund Husserl (1859-1938) ê o fundador da Fenomenologia. Husserl procurou descrever acuradamente o mundo como aparece, em todos os seus aspectos na consciência, buscando insaciavelmente rigor absoluto. Para ele não importa a relação do fenômeno com o mundo exterior. $\mathrm{O}$ fenômeno fica totalmente encerrado no campo imanente da consciência. Interessa-se pelo fenômeno puro, tal como se mostra na consciência. Fenômıeno com sentido mais subjetivo. Fenômeno é tudo aquilo de que podemos ter consciência, de qualquer modo que seja ZILLES ${ }^{9}$.

Husserl entende por fenomenologia a análise descritiva das vivências da consciência depurada de seus elementos empíricos para descobrir e aprender as essências diretamente na intuição, pois, segundo ele, a consciência é intencionalidade. Por intencionalidade entende que "a consciência está sempre voltada para algo, que ela não é, portanto, uma atividade construída de atos como os de significar, perceber, imaginar, desejar, pensar, querer, agir, etc." ZILLES .

Toda consciência está dirigida para algo, é intencional. Este fenômeno de intencionalidade Husserl chama vivência.

A Fenomenologia é uma ciência vigorosa que começa com a descrição do vivido. Propõe-se descrever os atos intencionais da consciência e dos "objetos" por eles visados. Reconhece que estes atos são de um eu que pensa o mundo ZILLES ${ }^{9}$.

A Fenomenologia constitui-se cono uma atitude ou postura filosófica radical e como um movimento de idéias com método próprio, o método Fenomenológico, visando a dar consistência científica à filosofia.

\subsection{Procedimentos}

$\mathrm{O}$ acesso às Instituições deu-se através de um ofício que solicitava a realização do estudo e apresentava o aluno.

Esse ofício nós entregamos pessoalmente a Enfermeiros - Diretores dos Serviços de Enfermagem.

A autorização nos foi concedida no momento deste contato com exceção de uma Instituição.

O Instrumento utilizado foi um roteiro de entrevista contendo temas abertos relacionados com o plantão notumo e o repouso.

Este instrumento foi sendo adequado conforme as entrevistas foram acontecendo.

A técnica utilizada para a coleta de dados foi a Entrevista não estruturada e focalizada.

Não houve iujentificação de Instituições, de unidade hospitalar ou do Entrevistado. Cada Entrevistado recebeu um pseudônimo para garantir o anonimato.

Procuramos iniciar a entrevista com um diálogo esclarecedor da pesquisa e que despertasse $o$ interesse e a confiança do entrevistado.

$\mathrm{Na}$ medida do possível desenvolvemos a entrevista em locais com uma menor interferência de terceiros. Inclusive objetivando conseguir maior naturalidade, espontaneidade e veracidade no diálogo ocorrido.

Após obtermos o consentimento gravamos a entrevista como o primeiro passo da coleta de dados. Como utilizamos o método fenomenológico, este apresenta as seguinte etapas: a coleta de dados, a análise do material, a interpretação dos resultados, a síntese dos achados e a re-teorização.

Cada entrevista foi transcrita cuidadosamente para obtermos uma real descrição do fenômeno. Foi um trabalho exaustivo, porém gratificante.

A análise foi realizada sobre essas transcrições. Começou com uma leitura do conjunto dos depoimentos para ter uma idéia geral sobre o assunto, tal como ele foi tratado pelos respondentes.

A seguir, analisamos um a um, dividindo as sentenças em "unidades de sentido", enumerando-as. Esta etapa é a redução fenomenológica. É onde assumimos uma atitude psicológica aprendida pré-refletida, pré-reflexiva para captar a experiência do fenômeno.

Após a captação da verdadeira mensagem do sujeito, transponho sua descrição em linguagem psicológica. É a fase de transformação das unidades de significado em linguagem psicológica. Essa transposição é sempre interpretativa e representativa do fenômeno explicitado pelo sujeito. Usamos categorias psicologicas gerais.

Em seguida, buscamos as estruturas de significado do conjunto das respostas analisadas que se constituem nos achados da pesquisa. Partindo sempre da valorização da verdade, elabora-se uma descrição harmoniosa e consistente.

Finalizamos com o que tradicionalmente se denomina "discussão de resultados" e que no presente método denomina-se de Re-teorização, que é a volta à teoria anterior de acordo com a pesquisa desenvolvida incialmente na literatura disponível sobre o assunto. Com conseqüente aprofundamento de compreensão sobre o tema, descoberta de novos ângulos de análise ou no mínimo, muda-se a visão do pesquisador quanto 
ao fenômeno em estudo, que já é avançar o conhecimento.

\section{SIGNIFICADOS PERCEBIDOS E RE-TEORIZAÇĀO}

Foram analisadas 11 entrevistas que sintetizam os resultados desta pesquisa.

Dos relatos de vivências individuais foram colocados em relevo os modos particulares de compreensão do fenômeno e apresentamos de um modo mais geral o que cada pessoa manifestou, porém, respeitando a sua experiência.

Desta forma não se generalizam resultados e sim chega-se a uma sintese dos significados percebidos.

O significado do trabalho noturno 'foi percebido como de importância para o paciente e para a Instituição. Para o Enfermeiro percebemos a necessidade econômica e algumas expressões como: "A gente adquire muita liderança à noite"; "À noite a gente consegue ter uma visão global do Hospital"; “À noite não existe uma competição muito acirrada, significa ficar longe das fofocas e ter menos desgaste"; "A gente consegue ter autonomia no trabalho", que mostram o lado positivo do trabalho ric turno.

Significa também a possibilidade de ter outra atividade paralela corro um curso universitário ou outros cursos que só existem durante o dia.

Esses Enfermeiros, na sua grande maioria, trabalham à noite por necessidade da Instituição e econômica, apenas três entrevistados disseram que gostam de trabalhar à noite.

Por outro lado, significa trabalhar num horário atípico, que não é valorizado e que é cansativo, estressante e exige uma məior atenção e esta foi uma grande preocupação expressada, "se a gente não estiver atenta pode fazer besteira", ou "atenção maior pelo fato do raciocínio estar mais lento, da pessoa estar mais lerda. .. atenção para ter a percepção das coisas que tem de dia", "às 4 h da manhã você perde a noção das coisas, fica diff́cil para escrever".

Percebemos no lado psicológico que: "Trabalhar à noite dá uma certa melancolia, uma tristeza. . . "É um pouco deprimente, psicologicament $\epsilon$ niuito desgastante".

No trabalho noturno existe uma sotrecarga de funçōes, o Enfermeiro faz muitas atividades que não são da sua alçada. Isto é decorrente da falta e/ou insuficiência dos serviços de apoio.

À noite, o Enfermeiro sente-se muito isolado, com acesso a poucas informações.

"Sem dúvida, o trabalho notumo encurta a vida do indivíduo. É pouco reconhecido. Ele é um anônimo. Passa despercebido", esta afirmação sintetiza a realidade vivenciada no trabalho noturno do Enfermeiro.

Devido à natureza de o homem ser para a atividade diurna e de o organismo ter ritmos biológicos para cada função, sempre que ele tiver que trabalhar à noite a sua saúde estará prejudicada.

$\mathrm{O}$ organismo não consegue inverter os seus ritmos biológicos totalmente. $\mathrm{O}$ sono diurno $\varepsilon$ inferior ao noturno. Ocorre em intervalos curtos com sobressaltos e com diminuição do sono paradoxal que é responsável pelo relaxamento psíquico, prevenindo a fadiga mental. Agravado pelas condições ambientais como rứdos e iluminação.

Dormir ou simplesmente descansar por 30 minutos, 1 hora ou até 2 horas antes de ir para o trabalho significa preparar-se para o plantão. Serve de suporte psicológico para o momento em que a pessoa estiver extremamente exausta ela pensar "mas eu descansei, eu vou suportar esta jornada".

Percebemos que, durante o plantão noturno poucos Enfermeiros repousam e o significado, mesmo para quem não repousa, é de ser necessário pela longa duração da jornada e ainda à noite.

A pausa tem o significado valioso mesmo que seja de uns $15 \mathrm{~min}$. Cochilar ou dormir em cadeiras desconfortáveis dentro do local de trabalho, na claridade, sob o rufdo de aparelhos e equipamentos, no chão em colchonetes improvisados ou mesmo num sofá sem a mínima condição é o que constatamos. Esta realidade tão bem descrita pelos Enfermeiros $e ́$ injusta e indigna do ser humano.

Chegou a hora, à noite, o organismo quer descansar, os indicadores de tempo e os indicadores sociais confirmam que está na hora de dormir.

Sabe-se que, após 6 horas de vignlia iniciase um processo de fadiga dos neurônios, o nível de feedback positivo obviamente diminuirá tanto nos circuitos corticais como nos circuitos periféricos. Além disso, cada vez que um dos milhões de neurônios paralelos no circuito do feedback sai fora de atividade, a ausência desta contribuição para o feedback reduz a intensidade de excitabilidade dos demais neurônios. Chega um ponto que a atividade do feedback nầo pode mais manter $\mathrm{a}$ excitabilidade suficiente no sistema ativador reticular para os circuitos continuarem reverberando. Entretanto, é possível que o meio ambiental local dos neurônios também se altere com a secreção de substâncias transmissoras causando inibição após perfodos de atividade ou excitação após perfodos de inatividade GUYTON ${ }^{4}$. Como o Enfermeiro está trabalhando, ele se mantém em vignlia de forma forçada e é este ritmo forçado que provoca o desgaste diário crônico do trabalhador. $\mathrm{O}$ ritmo circadiano da alternância sono-vigńlia tenta adaptar-se a essa situação.

Ter o direito a uma pausa para repousar du- 
rante o plantão em condições dignas, em uma cama e fora do local de trabalho, onde outra pessoa ficou substituindo-o é uma reivindicação unânime entre os entrevistados. É também ser valorizado. Valorizado pelo seu esforço, a sua dedicação e a sua disponibilidade para este horário tão penoso.

Relataram-me: "o melhor repouso que a gente faz ê à noite", "o horário nobre de sono é de 01 às $06 \mathrm{~h}$ da manhã", portanto o repouso mais importante é aquele que acontece à noite, durante o plantão ou na noite de folga.

A pausa durante o turno minimiza o desgaste crônico diário provocado pela privação do sono à noite.

Pode parecer uma utopia o Enfermeiro dormir ou simplesmente repousar durante um plantão notumo de 12 horas, seja por 1 ou 2 horas, de forma organizada e formal, mas essa prática existe informalmente, por que não oficializá-la?

O significado do repouso pós-plantão e: "um direito", "significa recuperar as energias", "É o tempo suficiente para repor as minhas energias, por enquanto", "É de um significado muito importante. É um repouso imprescindŕvel. É um repouso obrigatório", "E necessário. Apesar de acordar péssimo".

Esse repouso ocorre logo após a saŕda do plantão noturno, ou seja, de manhã, ocorre à tarde ou somente na noite de folga.

Existe uma confirmação com a teoria quando eles relatam acordarem péssimos, devagar, com o raciocínio lento, "quebrada, cansada. A gente não consegue desligar totalmente e delira no sono com tudo o que passou", porque o sono diumo mostra um número acentuadamente menor de fases 5 ou de sono paradoxal que garante o relaxamento psíquico, prevenindo a fadiga mental GUYTON ${ }^{4}$. Um dos entrevistados foi enfático: "Acordo desgastado. É um cansaço crônico. $O$ desgaste é acumulado e a longo prazo. O sono você não repōe. Ninguém acostuma a ficar sem dormir".

Houve quem disse: "Acordo descansada, porém com o disfoco de horário", "Horrível, com frio e até a aparência está afetada", "Parece que se torna pior. Acordo com frio, sem apetite, e terrivel" e "Acordo bem recuperada, mas se sou acordada, levo um susto. . . levanto achando que estou no trabalho". Estes entrevistados dormiam de dia.

As alterações na saúde do trabalhador noturno são sutis e eles não conseguem perceber mesmo trabalhando há muitos anos.

É freqüente o relato de estarem com uma sensibilidade maior, de se irritarem mais facilmente, de ter alterações de humor e ser tomado por uma certa depressão, do raciocínio estar mais lento e a memoria estar afetada e das alterações no apetite.
O trabalhador noturno ressente-se da privação da convivência familiar, do entrosamento e da participação social.

O autocuidado já está prejudicado pelo fato de o trabalho ser à noite. Com todas as conseqüências que já abordamos e agravado pela necessidade de um segundo emprego durante o dia. Dentro do possível, eles relatam que cuidam do que é prioritariamente básico para manterem-se em atividade. Seria descansar sempre que possível e dar atenção a alimentação.

O lazer é secundário, porém de importância reconhecida.

No final da entrevista todos emitiram sugestões: reinvindicando um repouso durante o plantão até aqueles que não repousam em hipótese alguma.

\section{CONCLUSĀO}

Concluindo, pessoalmente pensamos que a situação das condições de trabalho e de vida do pessoal de Enfermagem, mais especificamente do enfermeiro que trabalha à noite, é crítica, no entanto também é conformista e conivente.

A nosso ver há uma cumplicidade nesta situação, mas que se rompe no momento em que falhas graves acontecem e têm repercussão.

O trabalho noturno é cansativo, desgastante e prejudicial à saúde do trabalhador.

São desconhecidas as leis e a sua viabilidade de aplicação.

Pensamos que deveria existir um maior número de pessoal, uma escala organizada, um local adequado para o repouso durante o plantão e que este fosse oficializado. Paralelamente fossem espaçados os plantões noturnos independente do sistema de escalas.

Percebemos que ficou um pouco constrangedor para o Entrevistado descrever em detalhes as suas condições de repouso durante $o$ plantão. Um profissional de nfvel superior que conquistou um certo status dentro da sociedade descrever uma situação no trabalho cujas condições não condizem com este status chega a ser de certa forma, humilhante.

Porém, lembramos que qualquer transformação inicia-se no momento em que são vistos por nós os problemas, no momento em que não mais escondermos, não omitirmos nossa real situação e nossas condições de trabalho. Partindo dar para a busca do mínimo que preconiza"a legislação trabalhista.

Este não foi um estudo sobre uma única concepção de verdade, mas um relato da vivência de Enfermeiros que trabalham à noite, onde o que interessa era exatamente as diferentes vivências, os diferentes significados e conteúdo de uma mesma experiência de vida, vistos sob diferentes ângulos e vividos por diferentes pessoas - sentindo, vivendo, lutando, pensando. 


\section{REFERÊNCIAS BIBLIOGRÅFICAS}

1 FERREIRA, L.L. Trabalho em turnos: temas para discussão. Rev. Bras. Saúde Ocupacional, São Paulo, v. 15, n.58, p.27-32, abr/maio/jun. 1987.

2 FISCHER, F.M. et alii. Otimização do transporte de madeiras pela utilização dos princípios ergonômicos de trabalho. Faculdade de Ciências Farmacêuticas da USP, Faculdade de Saúde Pública da USP/Instituto de Ciências Biomédicas da USP. 1988, São Paulo, 78p.

3 GRANDJEAN, Etienne. O papel da ergonomia na medicina do trabalho. Rev. Bras. Saúde Ocupacional. São Paulo, v.8, n.32, p.31-36, out/nov/dez. 1980.

4 GUY TON, A.C. Sono e vigília. In: Tratado de fisiologia médica. 5 ed. Rio de Janeiro, Interamericana, 1976: Bibliografia: cap. 54, p.651-654.

5 LAUREL, Asa C. Processo de trabalho e saúde. Saúde em Debate, Rio de Janeiro, n. 11, p.8-29, 1981.
6 MARQUES, M.Y. Análise fenomenológica e fenomenografia: o estudo das relaçōes entre a pessoa e o mundo ao seu redor. In: SEMINÁRIO SOBRE PESQUISA FENOMENOLÓGICA NAS CIÊNCIAS HUMANAS E SOCIAIS, 1988, Porto Alegre. Anais... Rio de Janeiro: ANPESS e CBCISS, v.1, n.1, 1990, p.67-94.

7 RUTENFRANZ, Joseph, KNAUTH, Peter, FISCHER, Frida Marina. Trabalho em turnos e noturno. São Paulo, Hucitec, 1986.

8 SILVA, Vanda Elisa Felli da. Estudo sobre acidentes de trabalho ocorridos com trabalhadores de enfermagem de um hospital de ensino. Dissertação (Mestrado em Enfermagem) Escola de Enfermagem, Universidade de S. Paulo, 1988.

9 ZILLES, U. Edmund Husserl e o movimento fenomenologico. In: SEMINÁRIO SOBRE PESQUISA FENOMENOLÓGICA NAS CIÊNCIAS HUMANAS E SOCIAIS, 1988, Porto Alegre. Anais. . . Rio de Janeiro: ANPESS e CBCISS, v.1, n.1, 1990, p. 05-21. 